\title{
Androgen-responsive non-coding small RNAs extend the potential of HCG stimulation to act as a bioassay of androgen sufficiency
}

\author{
M E Rodie', M A V Mudaliar',3, P Herzyk 2,4, M McMillan', M Boroujerdi', S Chudleigh5, E S Tobias 1,3,6 and \\ S F Ahmed' ${ }^{1}$
}

${ }^{1}$ Developmental Endocrinology Research Group, University of Glasgow, Glasgow, UK, ${ }^{2}$ Glasgow Polyomics, ${ }^{3}$ Glasgow Molecular Pathology Node and ${ }^{4}$ Institute of Molecular Cell and Systems Biology, College of Medical, Veterinary and Life Sciences, University of Glasgow, Glasgow, UK, ${ }^{5}$ Department of Molecular Haematology, and ${ }^{6}$ Academic Medical Genetics and Pathology, Laboratory Medicine Building, Queen Elizabeth University Hospital, University of Glasgow, Glasgow, UK

\author{
Correspondence \\ should be addressed \\ to S F Ahmed \\ Email \\ Faisal.ahmed@glasgow.ac.uk
}

\section{Abstract}

Background: It is unclear whether a short-term change in circulating androgens is associated with changes in the transcriptome of the peripheral blood mononuclear cells (PBMC).

Aims and methods: To explore the effect of hCG stimulation on the PBMC transcriptome, 12 boys with a median age (range) of 0.7 years $(0.3,11.2)$ who received intramuscular hCG 1500 u on 3 consecutive days as part of their investigations underwent transcriptomic array analysis on RNA extracted from peripheral blood mononuclear cells before and after hCG stimulation.

Results: Median pre- and post-hCG testosterone for the overall group was $0.7 \mathrm{nmol} / \mathrm{L}(<0.5,6)$ and $7.9 \mathrm{nmol} / \mathrm{L}(<0.5$, $31.5)$, respectively. Of the 12 boys, $3(25 \%)$ did not respond to hCG stimulation with a pre and post median serum testosterone of $<0.5 \mathrm{nmol} / \mathrm{L}$ and $<0.5 \mathrm{nmol} / \mathrm{L}$, respectively. When corrected for gene expression changes in the nonresponders to exclude hCG effects, all 9 of the hCG responders consistently demonstrated a $20 \%$ or greater increase in the expression of piR-37153 and piR-39248, non-coding PIWI-interacting RNAs (piRNAs). In addition, of the 9 responders, 8, 6 and 4 demonstrated a 30, 40 and 50\% rise, respectively, in a total of 2 further piRNAs. In addition, 3 of the responders showed a $50 \%$ or greater rise in the expression of another small RNA, SNORD5. On comparing fold-change in serum testosterone with fold-change in the above transcripts, a positive correlation was detected for SNORD5 $(P=0.01)$.

Conclusions: The identification of a dynamic and androgen-responsive PBMC transcriptome extends the potential value of the hCG test for the assessment of androgen sufficiency.

\section{Introduction}

Sex-specific differences in anatomic, physiological and behavioural phenotypes are commonly found in many species, including humans, and are considered to be due to a combination of the effect of sex hormones and genetics (1). These sex differences are also illustrated by tissuespecific gene expression in several organs (2). The existence of an altered pattern of gene expression in androgen- responsive tissues, such as genital skin fibroblasts obtained from people with androgen insensitivity syndrome (AIS) (3), points to the likelihood that this sex-specific gene expression is, at least, partly androgen dependent. It has also been suggested that the altered transcriptomic patterns observed in the genital skin fibroblasts in AIS may be due to long-term, programmed effects of altered
C 2017 The authors Published by Bioscientifica Ltd. Printed in Great Britain 
androgen signalling during prenatal development (4). However, changes in circulating proteins, such as sex hormone-binding globulin (SHBG), can occur over a period of few days following androgen exposure, and this change has been used to assess androgen sensitivity, sometimes after stimulation of testosterone production with human chorionic gonadotropin (hCG) $(5,6)$. It is unclear whether androgens, in this context, can also induce short-term changes in gene expression. Widespread and acute changes in gene expression in response to androgens have indeed been described in other models (7). The current study was, therefore, performed to investigate the existence of an androgen-responsive gene expression pattern that would change over a relatively short period in boys in response to androgens. Given that a sex-specific gene expression pattern exists in peripheral blood mononuclear cells (PBMCs), which are known to express the androgen receptor (AR) $(8,9)$, the study was specifically designed at studying transcriptional changes in these cells in a group of boys undergoing investigations for a suspected disorder of sex development (DSD) by hCG stimulation. It was anticipated that not only would this study provide valuable insight into the wider effects of androgens, but it would also improve the utility of the hCG stimulation test and the diagnosis of functional androgen deficiency.

\section{Methods}

\section{Patients}

Between 2011 and 2014, 12 boys attending the endocrine service at the Royal Hospital for Children, Glasgow for an hCG stimulation test for investigation of 46, XY DSD were recruited following informed consent. The hCG stimulation protocol included intramuscular hCG (Pregnyl, Organon) 1500u on 3 consecutive days with blood sampling on Day 1, immediately before the first injection, and on Day 4, a day after the third injection. At each visit, the boys were also examined and the External Masculinisation Score (EMS) was calculated as described before (10). The group of boys was divided into two groups, those with an EMS of less than 8 and another with an EMS of 8 or more.

\section{Hormone assays and AR gene analysis}

All blood samples were collected in the morning, processed and stored at $-20^{\circ} \mathrm{C}$. Gonadotrophins were measured by a chemiluminescent microparticle immunoassay on the Architect ci1600 (Abbott Laboratories Diagnostics, Chicago, IL). The lower limit of follicle-stimulating hormone (FSH) and luteinising hormone (LH) detection was $0.1 \mathrm{IU} / \mathrm{L}$ and inter- and intra-assay precision (coefficient of variation, CV) for both $\mathrm{LH}$ and FSH were less than $5 \%$ at levels of $0.2 \mathrm{IU} / \mathrm{L}$ and $2.3 \mathrm{IU} / \mathrm{L}$ for $\mathrm{LH}$ and $0.6 \mathrm{IU} / \mathrm{L}$ and $4.7 \mathrm{IU} / \mathrm{L}$ for FSH. Anti-Mullerian hormone (AMH) was measured using enzyme-linked immunosorbent assay using Beckman Gen II assay (Beckman Coulter, Indianopolis, IN). The functional sensitivity was $1.5 \mathrm{pmol} / \mathrm{L}$ and the inter- and intra-assay CVs over the concentration range of $5-70 \mathrm{pmol} / \mathrm{L}$, was $3.8-17.3 \%$ and $5.3-11.4 \%$, respectively. Total testosterone and androstenedione were measured by LC MS/MS as described previously (11) using the Xevo TQS Tandem Mass Spectrometer (Waters Corporation, Milford, MA). Steroids were extracted from serum/plasma using Biotage supported liquid extraction (SLE), automated on the CTC PAL (MicroLiter Analytical Supplies Inc, Suwanne, Georgia), followed by Ultra-Performance Liquid Chromatographic separation. The lower limits of testosterone and androstenedione detection were $0.18 \mathrm{nmol} / \mathrm{L}$ and $0.09 \mathrm{nmol} / \mathrm{L}$, respectively. Where a baseline testosterone level was not available due to poor sample quality, a previous recent testosterone level was used. The AR gene (AR) for each patient was analysed by Sanger sequencing.

\section{RNA extraction}

For RNA extraction, blood was collected into EDTA and red cell lysis solution (Qiagen) was added. A total white cell count was performed and mononuclear cells were isolated by Ficoll gradient centrifugation. Total RNA was extracted from these cells on the Qiacube (Qiagen) with an RNA blood mini kit (Qiagen) according to the manufacturer's instructions. The RNA was resuspended in nuclease-free $\mathrm{dH}_{2} \mathrm{O}$ and concentration was measured using the Nanodrop Spectrophotometer (Thermo Fisher Scientific) before being stored at $-80^{\circ} \mathrm{C}$ in aliquots. RNA integrity numbers (RIN) were calculated using the Agilent 2100 Bioanalyser, version 2.6 (Agilent). Median white cell count on Day 1 and 4 was $12.6 \times 10^{9} / \mathrm{L}(6.3,26.4)$ and $17.2 \times 10^{9} / \mathrm{L}(2.7,25.5)$ respectively $(P=0.77)$. Median RNA concentration in the samples collected on Day 1 and 4 was $75 \mathrm{ng} / \mu \mathrm{L}(46,117)$ and $62 \mathrm{ng} / \mu \mathrm{L}(16,128)$, respectively $(P=0.88)$. Median RIN was also similar in the samples on Day 1 and 4 at 8.7 (3.8, 9.4) and 7.6 $(3.8,9.7)$, respectively $(P=0.90)$. 


\section{Microarray}

The WT plus kit (Affymetrix) was used to prepare amplified and biotinylated sense-stranded DNA targets using a reverse transcription priming method. After reverse transcription with random primers, microarray hybridization was performed on Human Transcript Array (HTA) 2.0 (Affymetrix) for all 12 paired RNA samples. The HTA 2.0 design contains more than 6 million distinct probes covering coding and non-coding transcripts. Seventy percent of the probes cover exons for coding transcripts, and the remaining $30 \%$ of probes on the array cover exon-exon splice junctions and non-coding transcripts. For simplicity, transcript clusters are described as genes.

\section{Transcriptome analysis}

Robust Multi-array Average (RMA) normalization was performed using Transcriptome Analysis Console 2.0 (Affymetrix) and then unsupervised hierarchical clustering analysis was performed in Partek Genomic Suite (Partek Inc, St Louis, MO). Gene expression data were log transformed and subsequent analysis was performed using Significance Analysis of Microarrays (SAM) package in the publicly available statistical computing language $\mathrm{R}$ (http://www.r-project.org). The programme was run using the response type as 'two class unpaired' based on 100 permutations using SAM, version 5.0. The significant genes were selected on the combined criteria of $\leq 5 \%$ false discovery rate and $\geq 1.5$ fold-change score. Gene transcripts were identified using The Human Genome Browser at UCSC (12). The cases were divided into those whose serum testosterone rose on hCG stimulation (responders) and those who did not show a testosterone rise (non-responders). To exclude the possible effects of hCG, as opposed to testosterone, on gene expression, fold-change in gene expression in the responders was divided by the mean fold-change expression of the non-responders and a fold-change threshold of 1.2 was applied subsequently to filter the transcripts, which were significantly upregulated or down-regulated.

\section{Statistical analysis}

All data are described as medians and ranges. Differences between patient groups were analysed using Student's $t$-test and correlations between individual gene transcripts and testosterone levels were calculated using Pearson's correlation coefficient in Minitab V.16 (Minitab).

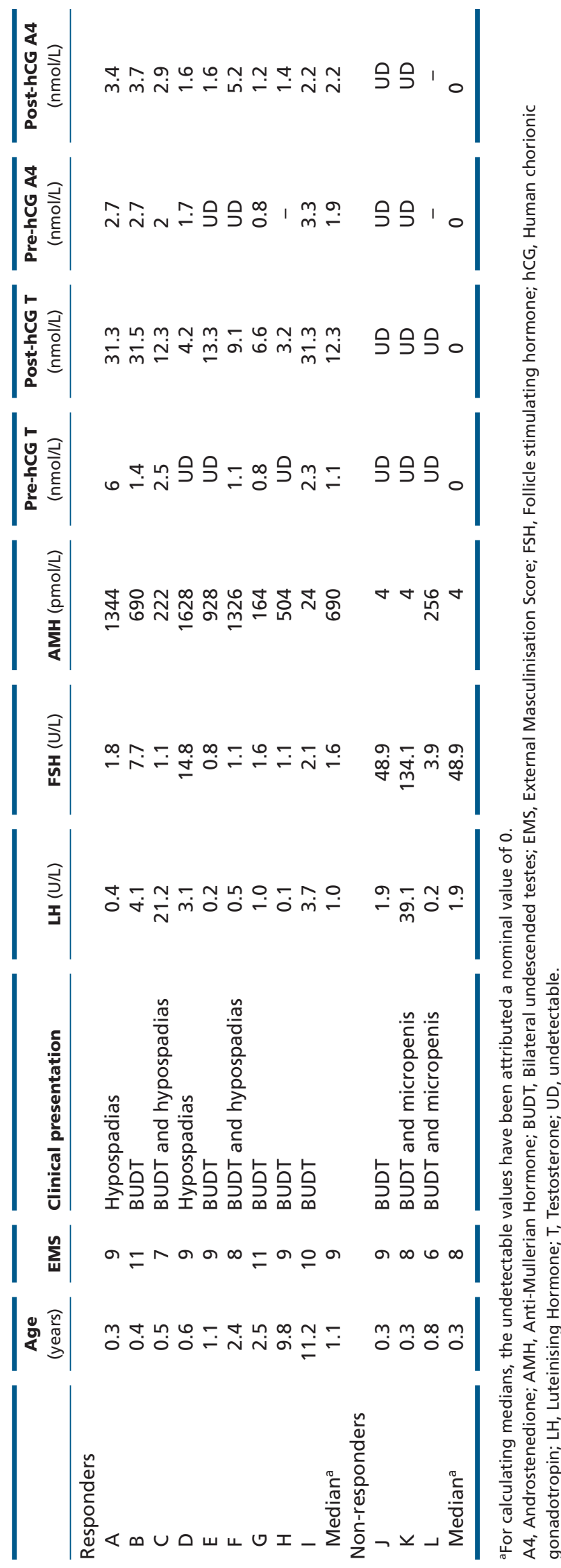

www.eje-online.org 
Table 2 Relationship of post-hCG transcriptome to EMS, age, basal T and peak T.

\begin{tabular}{|c|c|}
\hline & Transcript ID \\
\hline EMS $<8$ vs $\geq 8$ & - \\
\hline Age $<1$ vs $\geq 1$ & $\begin{array}{l}\text { TCOY000099.hg.1 } \\
\text { TCOY000204.hg. } 1\end{array}$ \\
\hline Basal T UD vs $\geq 0.5$ & $\begin{array}{l}\text { TC12000057.hg. } 1 \\
\text { TC06001608.hg. } 1\end{array}$ \\
\hline Peak T UD vs $\geq 0.5$ & - \\
\hline
\end{tabular}

\begin{tabular}{l} 
Gene \\
\hline- \\
uc011 $\mathrm{nby} .2$ \\
uc011 $\mathrm{nbq} .1$ \\
uc010sem.1 \\
uc003ofi. 1 \\
-
\end{tabular}
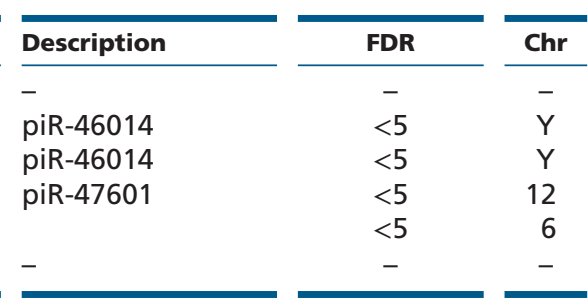

Post test genes were analysed to look at the effects of EMS, age, basal T and peak T using $\geq 1.5$ fold difference filter. The transcript ID is given as well as the gene name (12) where available.

Chr, Chromosome number; EMS, External Masculinisation Score; FDR, False Discovery Rate; T, testosterone; UD, undetectable.

\section{Results}

\section{Description of cases}

The majority of the boys had bilateral undescended testes, hypospadias, micropenis or a combination of these (Table 1). The median age (range) at hCG stimulation was 0.7 years $(0.3,11.2)$ and the median EMS was $9(6,11)$. Of the 12 boys, 9 (75\%) showed a rise in serum testosterone after hCG stimulation (responders) and the remaining 3 (25\%) did not (non-responders) (Table 1). Median foldchange in serum testosterone on Day 4 was $8.3(4.9,26.6)$ in the responders. Medium AMH in the responders and non-responders was $690 \mathrm{pmol} / \mathrm{L}(24,1628)$ and $4 \mathrm{pmol} / \mathrm{L}$ $(4,256)(P<0.01)$. A genetic mutation in $A R$ was excluded by genetic analysis in all the boys who underwent $A R$ gene sequencing (8 out of 9 responders and all the non-responders).

\section{Relationship of pre-hCG and post-hCG transcriptome to clinical characteristics}

Unsupervised hierarchical clustering analysis did not reveal any clustering patterns in the gene transcripts. On assessing the transcriptome pre-hCG and comparing the pattern in those with an EMS of 8 or more with those with an EMS of less than 8, and applying a fold-change filter of 1.5 , there were no significant differences detected. Further analysis was performed to determine whether there was any age dependency in the transcriptome and the pattern was compared for those with an age less than 1 year with those who were aged 1 year or older and no significant differences were found for the prehCG gene transcripts. There were also no differences between the pre-hCG transcripts with a detectable and undetectable testosterone. When the post-hCG transcriptome was studied, 2 transcripts were identified from the Y chromosome, which were age dependent, and 2 transcripts were identified from chromosomes 6 and 12, which were dependent on the basal testosterone level. These results are shown in Table 2.

\section{Comparison of hCG responders to non-responders}

The overall pattern of up- and downregulation of genes in the responders and non-responders did reveal differences (Fig. 1). On correction for gene expression changes in the non-responders, all 9 of the responders demonstrated a $20 \%$ or greater increase in the expression of $p i R-37153$ and piR-39248, non-coding PIWI-interacting RNAs. In addition, $8(89 \%), 6(67 \%)$ and $4(44 \%)$ of the responders demonstrated a 30, 40 and 50\% rise, respectively, in a total of 2 other piRNAs (Table 3). In addition, 3 (33\%) of the
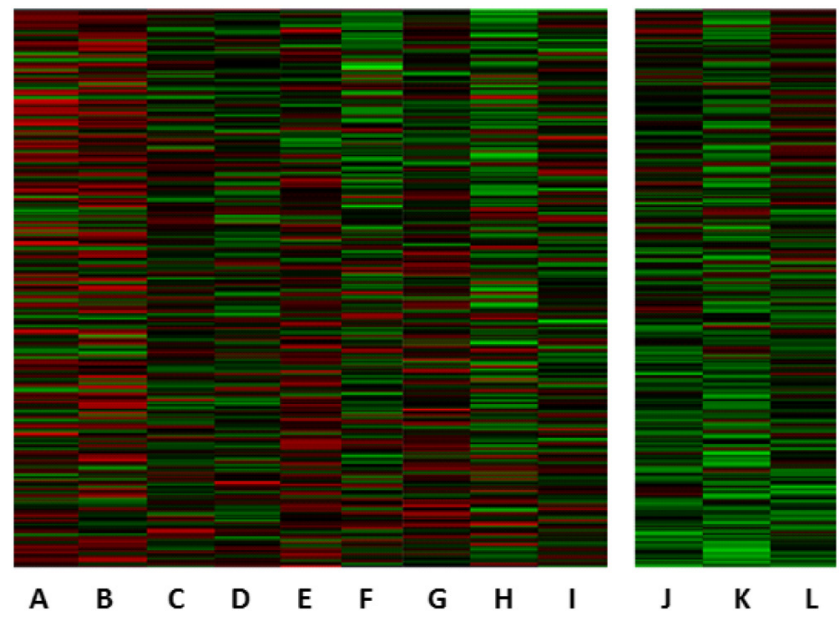

Figure 1

Gene expression changes in patients on hCG stimulation. Individual transcripts are shown in rows and each column represents a patient. Increasing red intensity corresponds to higher relative transcript levels compared to the mean expression level. Increasing green intensity corresponds to relatively decreased transcript levels. Patients $\mathrm{J}, \mathrm{K}$ and $\mathrm{L}$ are those who did not show a rise in serum testosterone following hCG stimulation. 
Table 3 Fold change in gene expression in the responders divided by the mean fold change expression of the non-responders.

\begin{tabular}{l}
\hline Gene name \\
\hline piR-37153 \\
piR-39248 \\
piR-39248 \\
piR-39248 \\
piR-53026 \\
piR-40996 \\
piR-40996 \\
SNORD5 \\
piR-61077 \\
piR-40996 \\
- \\
RNY5
\end{tabular}

\begin{tabular}{l} 
Transcript ID \\
\hline TC11001678.hg.1 \\
TC15000925.hg.1 \\
TC15000925.hg.1 \\
TC15000925.hg.1 \\
TC17001289.hg.1 \\
TC22000745.hg.1 \\
TC22000745.hg.1 \\
TC18000313.hg.1 \\
TC09001246.hg.1 \\
TC22000745.hg.1 \\
TC15000899.hg.1 \\
TC12001420.hg.1
\end{tabular}

\begin{tabular}{l}
\hline Gene symbol \\
\hline DQ599087 \\
DQ601182 \\
DQ601182 \\
DQ601182 \\
DQ585914 \\
DQ572884 \\
DQ572884 \\
- \\
DQ594965 \\
DQ572884 \\
DQ572592 \\
NR_001571
\end{tabular}

\begin{tabular}{c}
\hline Chromosome \\
\hline 11 \\
15 \\
15 \\
15 \\
17 \\
22 \\
22 \\
18 \\
9 \\
22 \\
15 \\
12
\end{tabular}

\begin{tabular}{cc}
\hline$\%$ Change \\
\hline$\uparrow 20$ \\
$\uparrow 20$ \\
$\uparrow 30$ \\
$\uparrow 40$ \\
$\uparrow 40$ \\
$\uparrow 40$ \\
$\uparrow 50$ \\
$\uparrow 50$ \\
$\uparrow 60$ \\
$\uparrow 60$ \\
$\uparrow 60$ \\
$\uparrow 60$
\end{tabular}
Number of patients

Fold change in gene expression in the responders was divided by the mean fold change expression of the non-responders and a fold-change threshold of 1.2 was applied subsequently to filter the transcripts which were significantly up or down regulated. These are shown in the table with the gene name, symbol and chromosome number.

responders showed a 50\% or greater rise in the expression of SNORD5, a small nucleolar RNA. Fold-change in testosterone was compared with fold-change in the transcripts listed in Table 3 and a, and positive correlation was only detected in the expression of SNORD5 $(P=0.01)$ (Fig. 2).

\section{Discussion}

Previous studies that have adopted a non-selective transcriptomic approach have shown the existence of gender-specific differences in a wide range of genes in PBMC $(13,14,15)$ and by studying a group of people with a wide range of conditions affecting sex development, the investigators had hypothesized that these differences were a function of programming by androgens, most likely

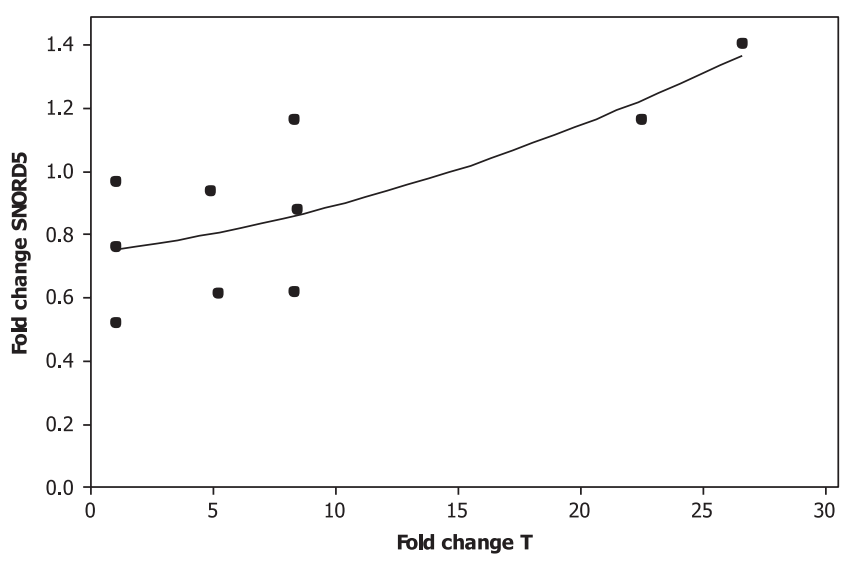

Figure 2

Correlation between fold change in SNORD5 gene expression and fold change in serum testosterone $(P=0.01)$. during embryonic development (8). Gene expression of several genes in a wide range of tissues and experimental models has been demonstrated to change following testosterone exposure $(16,17,18)$. We adopted a different approach to previous investigators as we were interested in identifying a pattern of change in gene expression that would indicate androgen responsiveness. In the current study, we have demonstrated that there is indeed a pattern of gene expression that can be detected in PBMC and that may also be responsive to acute changes in testosterone.

Specifically, we have identified several non-coding PIWI-interacting RNA (piRNAs) transcripts that seemed to be androgen responsive and only rose in those boys who showed a rise in testosterone following hCG stimulation. PiRNAs are 24-32 nucleotides in length and are the least investigated class of small RNA molecules $(19,20)$. The main function of these non-coding RNAs is gene silencing by the repression of transposable elements (TEs) in the germ line, and this role is highly conserved across all animal species $(21,22,23)$. PIWI proteins are primarily expressed in germ cells and in both mouse and fruit fly, mutations of genes encoding PIWI proteins result in de-repression of TEs in the germline, leading to male sterility $(24,25)$. PiRNA expression in rat testes has previously been reported to be responsive to testosterone exposure, and this response has been postulated as one of the mechanisms that allows testosterone to regulate testis function $(26,27)$.

In addition to the piRNAs, the PBMC from the boys who showed a rise in testosterone also demonstrated a rise in gene expression of SNORD5, and this rise was significantly correlated with the rise in testosterone. SNORD5 is a small nucleolar RNA (snoRNA), which also belongs to the family of small, non-coding RNAs. 
SNORD5 is a C/D box type of snoRNA expressed in several tissues (28) and although it is primarily associated with methylation, these RNAs have also demonstrated gene expression flexibility (29). However, its reported function of methylation is interesting in the current context, as it suggests that this may be one of the mechanisms that explains the epigenetic actions of testosterone described in previous reports $(30,31)$.

Human chorionic gonadotropin (hCG) is a glycoprotein that has an alpha subunit identical to that of LH (32), thus allowing it to be used clinically in the hCG stimulation test to assess the ability of the testes to produce testosterone (33). This ability to stimulate testosterone production has been used to determine the presence of functioning testes in boys with a suspected XY DSD (34). The hCG stimulation test has also been shown to aid the diagnosis of testosterone biosynthetic defects such as $5 \alpha$ reductase deficiency and $17 \beta$ hydroxysteroid dehdrogenase deficiency (35). Prognostically, hCG stimulation performed in early childhood may predict testis function during adolescence $(36,37)$, and some have used it to assess androgen sensitivity by measuring the fall in serum SHBG following hCG-stimulated rise in testosterone (6). In the case of suspected XY DSD, a normal rise in testosterone with no evidence of a biosynthetic defect is the commonest outcome of the test, and in this case, the boy is often suspected of having androgen insensitivity. A firm diagnosis of AIS requires the confirmation of a mutation in the androgen receptor gene $(A R)$. However, recent studies suggest that the molecular genetic abnormality in $A R$ may not necessarily reside in the conventional coding region within the gene (38). Whilst there is a school of thought that molecular genetic investigations can be performed in parallel with biochemical evaluation, the current study suggests that the utility of conventional biochemical investigations such as the hCG stimulation test, itself, can include a molecular genetic component that aids the diagnosis of androgen deficiency and perhaps, androgen resistance. Our cases did not include any with a molecular genetic diagnosis of androgen insensitivity due to a mutation in $A R$, and it would be helpful to perform the same study in a group of boys with a confirmed abnormality in $A R$. Although androgen-responsive circulating proteins such as SHBG have been measured previously (6), this test has not been considered to be sufficiently reliable to become common practice. More recently, another androgenresponsive protein in the genital skin fibroblasts has been reported to have a greater discriminant value for androgen sensitivity (38). Genital skin fibroblast studies have also previously reported an androgen-dependent transcriptome, which could differentiate between people with and without androgen sensitivity (3). Given the small number of cases studied in the current report and the relatively small, yet consistent, fold changes, we did not seek to correlate the array findings with quantitative real-time PCR. However, in the current study, we do raise the prospect of assessing androgen sufficiency and, possibly, even androgen resistance less invasively by studying an androgen-responsive change in expression of a small panel of genes in PBMCs extracted from the serial blood samples collected as part of the hCG stimulation test, which is commonly performed for investigating male hypogonadism. Given that testosterone action in $\mathrm{T}$ cells may be mediated by a combination of genomic and non-genomic AR signalling, the potential for PBMCs as a bioassay of androgen signalling needs further exploration (39). Furthermore, the current study also lends weight to the possibility that androgens may modulate immune function $(40,41)$.

In summary, the existence of an androgen-responsive group of small RNAs that are measurable in peripheral mononuclear blood cells and that change over the short duration of a hCG stimulation test raise the prospect of combining the biochemical assessment of testosterone production with an objective molecular assessment of androgen sufficiency.

\section{Declaration of interest}

The authors declare that there is no conflict of interest that could be perceived as prejudicing the impartiality of the research reported.

\section{Funding}

M R was supported by the Glasgow Children's Hospital Charity. S F A and E S T are supported by a Scottish Executive Health Department grant for the Scottish Genomes Partnership. M A V M and E S T are supported by MRC/EPSRC Molecular Pathology Node funding and E S T is also supported by Wellcome Trust ISSF funding.

\section{Author contribution statement}

M E R was involved in performing the studies, analysing the data and preparing the first draft of the manuscript. $M A V M, P H$ and E S T were involved in performing and analysing the genomic data and revising the manuscript. $\mathrm{M} \mathrm{M}$ and $\mathrm{S} C$ were involving in assisting with sample collection and processing and revising the manuscript. $M$ B was involved in the statistical analysis of the data. S F A conceived the study, oversaw the progress, revised the manuscript and acts as the guarantor of the study. 


\section{Acknowledgements}

The authors would like to thank Jane McNeilly, Ethel McNeill, Victoria Fisher and Rajkumar Dhandayuthapani for technical assistance.

\section{References}

1 Ober C, Loisel DA \& Gilad Y. Sex-specific genetic architecture of human disease. Nature Reviews Genetics 20089 911-922. (doi:10.1038/ $\operatorname{nrg} 2415)$

2 Yang X, Schadt EE, Wang S, Wang H, Arnold AP, Ingram-Drake L, Drake TA \& Lusis AJ. Tissue-specific expression and regulation of sexually dimorphic genes in mice. Genome Research 200616 995-1004. (doi:10.1101/gr.5217506)

3 Holterhus PM, Deppe U, Werner R, Richter-Unruh A, Bebermeier JH, Wünsch L, Krege S, Schweikert HU, Demeter J, Riepe F et al. Intrinsic androgen-dependent gene expression patterns revealed by comparison of genital fibroblasts from normal males and individuals with complete and partial androgen insensitivity syndrome. BMC Genomics 20078 376. (doi:10.1186/1471-2164-8-376)

4 Holterhus PM, Hiort O, Demeter J, Brown PO \& Brooks JD. Differential gene-expression patterns in genital fibroblasts of normal males and 46, XY females with androgen insensitivity syndrome: Evidence for early programming involving the androgen receptor. Genome Biology 20034 R37. (doi:10.1186/gb-2003-4-6-r37)

5 Sinnecker GH, Hiort O, Nitsche EM, Holterhus PM \& Kruse K. Functional assessment and clinical classification of androgen sensitivity in patients with mutations of the androgen receptor gene. German Collaborative Intersex Study Group. European Journal of Pediatrics 1997156 7-14. (doi:10.1007/s004310050542)

6 Bertelloni S, Federico G, Baroncelli GI, Cavallo L, Corsello G, Liotta A, Rigon F \& Saggese G. Biochemical selection of prepubertal patients with androgen insensitivity syndrome by sex hormone-binding globulin response to the human chorionic gonadotropin test. Pediatrics Research 199741 266-271. (doi:10.1203/00006450199702000-00018)

7 Dorts J, Richter CA, Wright-Osment MK, Ellersieck MR, Carter BJ \& Tillitt DE. The genomic transcriptional response of female fathead minnows (Pimephales promelas) to an acute exposure to the androgen, 17beta-trenbolone. Aquatic Toxicology 200991 44-53. (doi:10.1016/j.aquatox.2008.10.002)

8 Liva SM \& Voskuhl RR. Testosterone acts directly on CD4+ T lymphocytes to increase IL-10 production. Journal of Immunology 2001 167 2060-7. (doi:10.4049/jimmunol.167.4.2060)

9 Holterhus PM, Bebermeier JH, Werner R, Demeter J, Richter-Unruh A, Cario G, Appari M, Siebert R, Riepe F, Brooks JD et al. Disorders of sex development expose transcriptional autonomy of genetic sex and androgen-programmed hormonal sex in human blood leukocytes. BMC Genomics 200910 292. (doi:10.1186/1471-2164-10-292)

10 Ahmed SF, Khwaja O \& Hughes IA. The role of a clinical score in the assessment of ambiguous genitalia. BJU International $2000 \mathbf{8 5}$ 120-124. (doi:10.1046/j.1464-410x.2000.00354.x)

11 Büttler RM, Martens F, Ackermans MT, Davison AS, van Herwaarden AE, Kortz L, Krabbe JG, Lentjes EG, Syme C, Webster R et al. Comparison of eight routine unpublished LC-MS/MS methods for the simultaneous measurement of testosterone and androstenedione in serum. Clinica Chimica Acta 2016454 112-118. (doi:10.1016/j. cca.2016.01.002)

12 Kent WJ, Sugnet CW, Furey TS, Roskin KM, Pringle TH, Zahler AM \& Haussler D. The human genome browser at UCSC. Genome Research 200212 996-1006. (doi:10.1101/gr.229102)

13 Whitney AR, Diehn M, Popper SJ, Alizadeh AA, Boldrick JC, Relman DA \& Brown PO. Individuality and variation in gene expression patterns in human blood. PNAS 2003100 1896-1901. (doi:10.1073/ pnas.252784499)
14 Eady JJ, Wortley GM, Wormstone YM, Hughes JC, Astley SB, Foxall RJ, Doleman JF \& Elliott RM. Variation in gene expression profiles of peripheral blood mononuclear cells from healthy volunteers. Physiological Genomics 200522 402-411. (doi:10.1152/ physiolgenomics.00080.2005)

15 Elliott RM, de Roos B, Duthie SJ, Bouwman FG, Rubio-Aliaga I, Crosley LK, Mayer C, Polley AC, Heim C, Coort SL et al. Transcriptome analysis of peripheral blood mononuclear cells in human subjects following a $36 \mathrm{~h}$ fast provides evidence of effects on genes regulating inflammation, apoptosis and energy metabolism. Genes Nutrition 20149 432. (doi:10.1007/s12263-014-0432-4)

16 Yonehara K, Suzuki M, Yamanouchi K \& Nishihara M. Expression analyses of sex steroid-regulated genes in neonatal rat hypothalamus. Journal of Reproduction and Development 200349 547-552. (doi:10.1262/jrd.49.547)

17 DePrimo SE, Diehn M, Nelson JB, Reiter RE, Matese J, Fero M, Tibshirani R, Brown PO \& Brooks JD. Transcriptional programs activated by exposure of human prostate cancer cells to androgen. Genome Biology 20023 research0032.1-research0032.12.

18 Peterson MP, Rosvall KA, Choi JH, Ziegenfus C, Tang H, Colbourne JK \& Ketterson ED. Testosterone affects neural gene expression differently in male and female juncos: a role for hormones in mediating sexual dimorphism and conflict. PLOS ONE 20138 e61784. (doi:10.1371/journal.pone.0061784)

19 Lin H \& Spradling AC. A novel group of pumilio mutations affects the asymmetric division of germline stem cells in the Drosophila ovary. Development 1997124 2463-2476.

20 Girard A, Sachidanandam R, Hannon GJ \& Carmell MA. A germlinespecific class of small RNAs binds mammalian Piwi proteins. Nature 2006442 (7099) 199-202. (doi:10.1038/nature04917)

21 Aravin AA, Naumova NM, Tulin AV, Vagin VV, Rozovsky YM \& Gvozdev VA. Double-stranded RNA-mediated silencing of genomic tandem repeats and transposable elements in the D. melanogaster germline. Current Biology 200111 1017-1027. (doi:10.1016/S09609822(01)00299-8)

22 Aravin A, Gaidatzis D, Pfeffer S, Lagos-Quintana M, Landgraf P, Iovino $\mathrm{N}$, Morris P, Brownstein MJ, Kuramochi-Miyagawa S, Nakano T et al. A novel class of small RNAs bind to MILI protein in mouse testes. Nature 2006442 203-207. (doi:10.1038/nature04916)

23 Grivna ST, Beyret E, Wang Z \& Lin H. A novel class of small RNAs in mouse spermatogenic cells. Genes Development 200620 1709-1714. (doi:10.1101/gad.1434406)

24 Carmell MA, Girard A, van de Kant HJ, Bourc'his D, Bestor TH, de Rooij DG \& Hannon GJ. MIWI2 is essential for spermatogenesis and repression of transposons in the mouse male germline. Developmental Cell 200712 503-514. (doi:10.1016/j.devcel.2007.03.001)

25 Vagin VV, Klenov MS, Kalmykova AI, Stolyarenko AD, Kotelnikov RN \& Gvozdev VA. The RNA interference proteins and vasa locus are involved in the silencing of retrotransposons in the female germline of Drosophila melanogaster. RNA Biology 20041 54-58. (doi:10.4161/rna.1.1.943)

26 Kang HJ, Moon MJ, Lee HY \& Han SW. Testosterone alters testis function through regulation of piRNA expression in rats. Molecular Biology Reports 201441 6729-6735. (doi:10.1007/s11033-014-3558-y)

27 Fu Q, Pandey RR, Leu NA, Pillai RS \& Wang PJ. Mutations in the MOV10L1 ATP hydrolysis motif cause piRNA biogenesis failure and male sterility in mice. Biology of Reproduction 201695103. (doi:10.1095/biolreprod.116.142430)

28 Balakin AG, Smith L \& Fournier MJ. The RNA world of the nucleolus: two major families of small RNAs defined by different box elements with related functions. Cell 199686 823-834. (doi:10.1016/S00928674(00)80156-7)

29 Dieci G, Preti M \& Montanini B. Eukaryotic snoRNAs: a paradigm for gene expression flexibility. Genomics 200994 83-88. (doi:10.1016/j. ygeno.2009.05.002)

30 Zhou L, Zhang X, Wu X, Yang H, Zhong K, Wang H, Zhou T, Sheng T, Tong Y, Fan D et al. Testosterone regulates Arp2/3 expression by DNA 
methylation in hippocampus. Molecular Neurodegeneration 20127 (Supplement 1) S27-S27. (doi:10.1186/1750-1326-7-S1-S27)

31 Ghahramani NM, Ngun TC, Chen P-Y, Tian Y, Krishnan S, Muir S, Rubbi L, Arnold AP, de Vries GJ, Forger NG et al. The effects of perinatal testosterone exposure on the DNA methylome of the mouse brain are late-emerging. Biology of Sex Differences 201458. (doi:10.1186/2042-6410-5-8)

32 Lapthorn AJ, Harris DC, Littlejohn A, Lustbader JW, Canfield RE, Machin KJ, Morgan FJ \& Isaacs NW. Crystal structure of human chorionic gonadotropin. Nature 1994369 455-461. (doi:10.1038/369455a0)

33 Winter JS, Taraska S \& Faiman C. The hormonal response to HCG stimulation in male children and adolescents. Journal of Clinical Endocrinology 197234 348-353. (doi:10.1210/jcem-34-2-348)

34 Grant DB, Laurance BM, Atherden SM \& Ryness J. HCG stimulation test in children with abnormal sexual development. Archives of Disease in Childhood $1976 \mathbf{5 1}$ 596-601. (doi:10.1136/ adc.51.8.596)

35 Greene S, Zachmann M, Manella B, Hesse V, Hoepffner W, Willgerodt $\mathrm{H} \&$ Prader A. Comparison of two tests to recognize or exclude 5 alpha-reductase deficiency in prepubertal children. Acta Endocrinologica (Copenh) 1987114 113-117. (doi:10.1530/ acta.0.1140113)

36 Segal TY, Mehta A, Anazodo A, Hindmarsh PC \& Dattani MT. Role of gonadotropin-releasing hormone and human chorionic gonadotropin stimulation tests in differentiating patients with hypogonadotropic hypogonadism from those with constitutional delay of growth and puberty. Journal of Clinical Endocrinology and Metabolism 200994 780-785. (doi:10.1210/jc.2008-0302)

37 Ishii T, Matsuo N, Sato S, Ogata T, Tamai S, Anzo M, Kamimaki T, Sasaki G, Inokuchi M, Hori N et al. Human chorionic gonadotropin stimulation test in prepubertal children with micropenis can accurately predict leydig cell function in pubertal or postpubertal adolescents. Hormone Research in Paediatrics 201584 305-310. (doi:10.1159/000439234)

38 Hornig NC, Ukat M, Schweikert HU, Hiort O, Werner R, Drop SL, Cools M, Hughes IA, Audi L, Ahmed SF et al. Identification of an AR-mutation negative class of androgen insensitivity by determining endogenous AR-activity. Journal of Clinical Endocrinology and Metabolism 2016101 4468-4477. (doi:10.1210/jc.2016-1990)

39 Benten WP, Becker A, Schmitt-Wrede HP \& Wunderlich F Developmental regulation of intracellular and surface androgen receptors in T cells. Steroids 200267 925-931. (doi:10.1016/S0039128X(02)00055-7)

40 Page ST, Plymate SR, Bremner WJ, Matsumoto AM, Hess DL, Lin DW, Amory JK, Nelson PS \& Wu JD. Effect of medical castration on CD4+ CD25+ T cells, CD8+ T cell IFN-gamma expression, and NK cells: A physiological role for testosterone and/or its metabolites. American Journal of Physiology 2006290 E856-E863 (doi:10.1152/ ajpendo.00484.2005)

41 Rais M, Wilson RM \& Urbanski HF. Messaoudi I.Androgen supplementation improves some but not all aspects of immune senescence in aged male macaques. Geroscience 2017. Epub (doi:10.1007/s11357-017-9979-5)

Received 19 May 2017

Revised version received 27 June 2017

Accepted 21 July 2017 